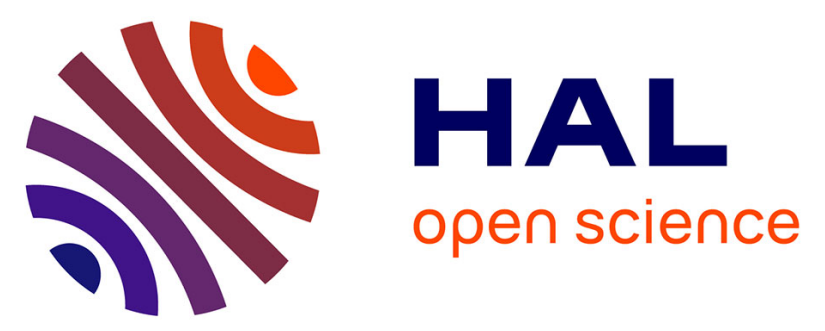

\title{
Exploitation of beehive products, plant exudates and tars in Corsica during the early Iron Age
}

Maxime Rageot, Kewin Peche-quilichini, Vanessa Py, Jean-Jacques Filippi, Xavier Fernandez, Martine Regert

\section{- To cite this version:}

Maxime Rageot, Kewin Peche-quilichini, Vanessa Py, Jean-Jacques Filippi, Xavier Fernandez, et al.. Exploitation of beehive products, plant exudates and tars in Corsica during the early Iron Age. Archaeometry, 2016, 58 (2), pp.315-332. 10.1111/arcm.12172 . hal-01236014

\section{HAL Id: hal-01236014 https://hal.science/hal-01236014}

Submitted on 1 Dec 2015

HAL is a multi-disciplinary open access archive for the deposit and dissemination of scientific research documents, whether they are published or not. The documents may come from teaching and research institutions in France or abroad, or from public or private research centers.
L'archive ouverte pluridisciplinaire HAL, est destinée au dépôt et à la diffusion de documents scientifiques de niveau recherche, publiés ou non, émanant des établissements d'enseignement et de recherche français ou étrangers, des laboratoires publics ou privés. 


\title{
EXPLOITATION OF BEEHIVE PRODUCTS, PLANT EXUDATES AND TARS IN CORSICA DURING THE EARLY IRON A GE*
}

\author{
M. RAGEOT ${ }^{1,2}$ K. PÊCHE-QUILICHINI ${ }^{3}$ V. PY ${ }^{4}$ J.-J. FILIPPI ${ }^{2}$ X. FERNANDEZ ${ }^{2}$ \\ and M. REGERT, ${ }^{1} \dagger$ \\ ${ }^{1}$ Université Nice Sophia Antipolis, CNRS, CEPAM, UMR 7264, 06300 Nice, France \\ ${ }^{2}$ Université Nice Sophia Antipolis, CNRS, ICN, UMR 7272, 06300 Nice, France \\ ${ }^{3}$ UMR 5140 Archéologie des sociétés méditerranéennes, 390 Avenue de Pérols 34970 Lattes, France \\ ${ }^{4}$ GEODE (Géographie de l'Environnement) UMR 5602, Maison de la Recherche de l'Université du Mirail, 5 Allées A. Machado, \\ 31058 Toulouse Cedex 9, France
}

\begin{abstract}
In the north-western Mediterranean area, the first Iron Age is characterized by intense contacts and cultural interactions between populations. Archaeological remains such as ceramic vessels or metal and glass objects are usually good indicators of the nature and the intensity of these exchanges, but can also be used to determine the way in which these populations were living at their time. In contrast, organic substances, despite their importance in a wide variety of activities, are rarely investigated due to their low degree of preservation. The recent discovery of a series of amorphous organic residues with adhesive properties at the site of Cuciurpula provided a unique opportunity to address questions related to the types of natural substances exploited, their provenance, their uses and their informational input to intercultural relationships. Our results, based on GC and GC-MS analysis of organic residues preserved at the site of Cuciurpula, provide strong evidence for the most southern use of birch bark tar in Western Europe, and also for the simultaneous use of this substance with pine resin. Beeswax was also identified in some samples. The combined study of residue composition, aspect and location on ceramic sherds reveals a variety of uses, highlighting a complex technical system.
\end{abstract}

KEYWORDS: BIRCH BARK TAR, PINE RESIN, BEESWAX, IRON AGE, CORSICA

\section{INTRODUCTION}

In Corsica, the Iron Age was a period of significant territorial, social and economic change, which has received scant attention from archaeologists until recently (Lechenault 2011; Garcia 2012). Indeed, research conducted on the island has been focused on the Bronze Age, which is characterized by huge building complexes including defensive structures, and on the civilizations of the Classical Age, namely the Phoenicians, Etruscans, Greeks and Romans (Pêche-Quilichini 2012a).

The village of Cuciurpula was discovered in 2003 by D. Martinetti and has been excavated by one of us (KPQ) since 2008. The archaeological investigations have allowed significant advances in the characterization of the settlement pattern, the spatial organization and the indigenous ceramic and metallic productions (Pêche-Quilichini 2012b). The site is located at an altitude of $1000 \mathrm{~m}$, in the south-central part of Corsica, on the Punta di Cuciurpula. This relief is considered

*Received 14 May 2014; accepted 21 November 2014

$\dagger$ Corresponding author: email martine.regert@cepam.cnrs.fr

(C) 2015 University of Oxford 
as a strategic belvedere on the Alta Rocca massif. It is also a transhumance pathway to the Coscionu plateau. Cuciurpula occupies a surface of approximately a dozen hectares and includes about 40 habitation units occupied at different times and surrounded by non-defensive enclosures (Fig. 1). It may be considered as the most important village known in Corsica in this period. Belonging to the Nuciaresa group, it is representative of the southern Corsica cultural context (Pêche-Quilichini et al. 2010; Pêche-Quilichini 2012b).

Among the habitation units, structure 1 (Fig. 1) was totally excavated between 2008 and 2010 . Within the stratigraphy of this structure, four phases were determined. Organic residues were found in three of them (phases 0,1 and 3). The first one, phase 0 (ninth to eighth centuries $\mathrm{BC}$ ), predates the house building. It is characterized by strong pottery manufacturing activity. The second, phase 1 (eighth century BC), corresponds to the main occupation of the house. After phase 1, this structure was not occupied for a while and phase 2 (beginning of the seventh century $\mathrm{BC}$ ) does not show any evidence of occupation. The last phase (phase 3, at the beginning of the sixth century BC) corresponds to the final stage of occupation (Fig. S1). This chronology is based on two ${ }^{14} \mathrm{C}$ dating measurements, obtained on charcoals, which have been detailed elsewhere (Pêche-Quilichini 2012b). The site of Cuciurpula was thus inhabited before the beginning of the colonization of Corsica by the Greeks (Alalia, the first Greek settlement in Corsica, dates from the middle of the sixth century BC: Jehasse 2003, 31). The reason why the inhabitants left the site at the beginning of the sixth century $\mathrm{BC}$ is still not understood but is probably not related to the Greek colonization.

Pottery fragments are the most abundant remains discovered on the site. The other main remains excavated are architectural structures, a few clues with regard to metallurgy and charcoals. In addition, several black amorphous organic residues have been discovered during

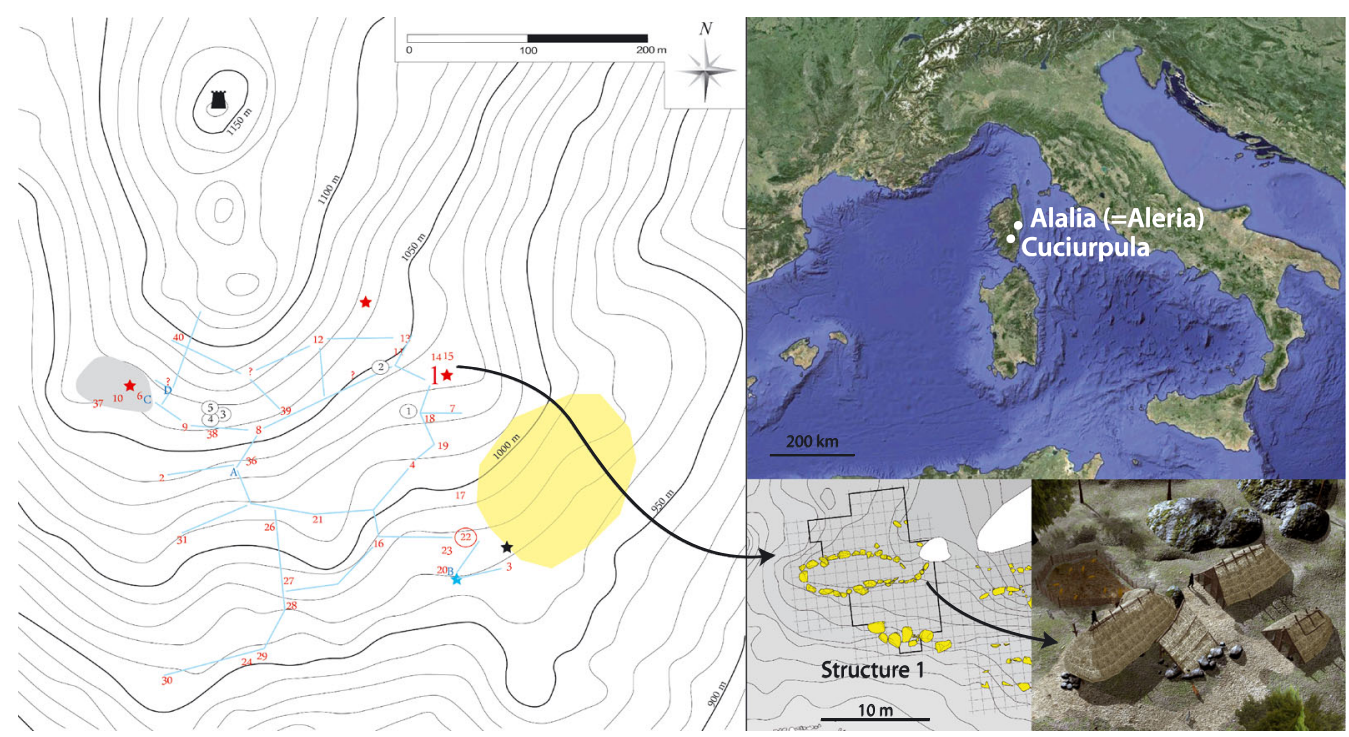

Figure 1 The location and site map for Cuciurpula, including a detailed map of habitation unit 1 (structure 1) and its hypothetical reconstitution (ㅇ L. Bergerot and K. Pêche-Quilichini). Red numbering, domestic structures; black numbering, excavated shelters; blue lettering, studied paths and their presumed extension (blue lines); red stars, quarries; blue stars, source; black stars, charcoal producer's house (20th century); black tower, medieval castrum; yellow area, presumed agricultural area; grey area, extension of fortified Final Bronze Age occupation. (See online for a colour version of this figure.) 
the excavation. Most of them were visible remnants, present on the surface of ceramic sherds; free lumps were also collected from the sedimentary matrix.

The discovery of several organic adhesives at Cuciurpula fills a gap in our knowledge on the exploitation of plant exudates in the north-western Mediterranean during the Iron Age, just before the colonization of Corsica by the Greeks.

Our purpose was, first, to determine the natural substances preserved at the site of Cuciurpula by using a combination of structural and separative methods (DI EI-MS, GC and GC-MS: Regert and Rolando 2002; Regert et al. 2003; Regert 2004, 2009). Beyond this objective, we aimed at understanding the role of the organic remains in improving and repairing pottery vessels. In a context of strong cultural contacts, we also wanted to highlight the standing, in the intercultural relationships, of the natural substances identified, and to explore the possible cultural influences and innovations in Corsica during the Iron Age. Finally, it was important to examine the ways of managing the natural substances involved in adhesive production by studying in detail the putative resources available close to the site and the choices made by the protohistoric inhabitants of Cuciurpula.

The identification of birch bark tar, pine resin and beeswax provides new data on substances mentioned by classical authors ${ }^{1}$ (Jehasse 2003) but rarely investigated in the archaeological record for the protohistoric period.

\section{THE AMORPHOUS ORGANIC RESIDUES DISCOVERED AT THE SITE OF CUCIURPULA}

In structure 1, a total of five free lumps and 53 sherds with visible black to brownish organic residues on their inner or outer surface were discovered and collected. Almost half of the sherd residues (25 out of 53) consisted of rough and brittle black deposits, which are usually linked with culinary activities, as already discussed in literature (Regert 2007). For this reason, these charred surface residues were not considered in this paper.

This paper is thus focused on a corpus of five free lumps and 31 visible residues preserved on 28 ceramic sherds (Table 1 ). The ceramic assemblages were highly fragmented. Therefore, at this stage of the study, it was not possible to establish correlations between the organic residues and pottery shape, size and volume. However, the organic remains seem to adhere to different kinds (size) and parts (rim, body and base) of vessels. The ratio between the sherds with organic residues and the whole potsherd corpus from phase 0 shows the highest percentage $(10 / 880$; i.e., 1.14\%). Lower ratios were obtained for phases 1 (11/5970; i.e., 0.18\%) and 3 (7/1250; i.e., $0.56 \%$ ). No further amorphous organic material was found for phase 2. Depending on their appearance (colour, thickness) and distribution on the sherd (inner or outer surface, near ancient cracks, surface coating etc.), three types of residues were distinguished (Fig. 2):

(i) long and thick bands of organic residues along the edges of ancient cracks, considered as mending adhesives (class A, 10 samples, including three from phase 0 , six from phase 1 and one from phase 3);

(ii) thin brownish deposits on the inner surface of pottery sherds that may be related to the use of a waterproofing agent or may result from the storage of adhesive substances (class B, eight samples, including three from phase 0 , three from phase 1 and two from phase 3 ); and

\footnotetext{
${ }^{1}$ See http://remacle.org/bloodwolf/erudits/plineancien/livre16.htm for Pliny the Elder, who mentioned birch in book 16 (XXX. (XVIII.) [3]), pine pitch in book 16 and beeswax in book 11 .
} 
M. Rageot et al.

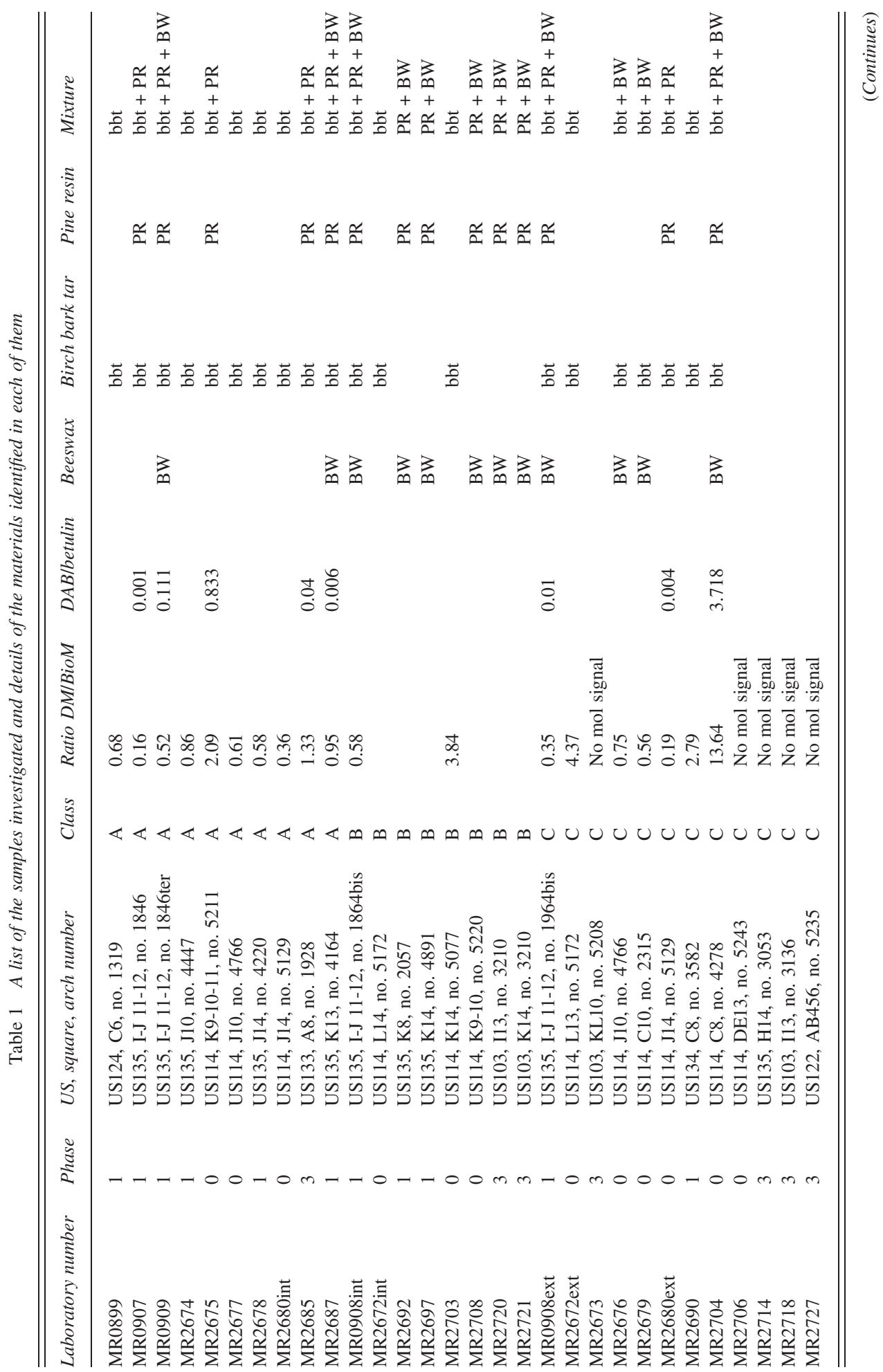




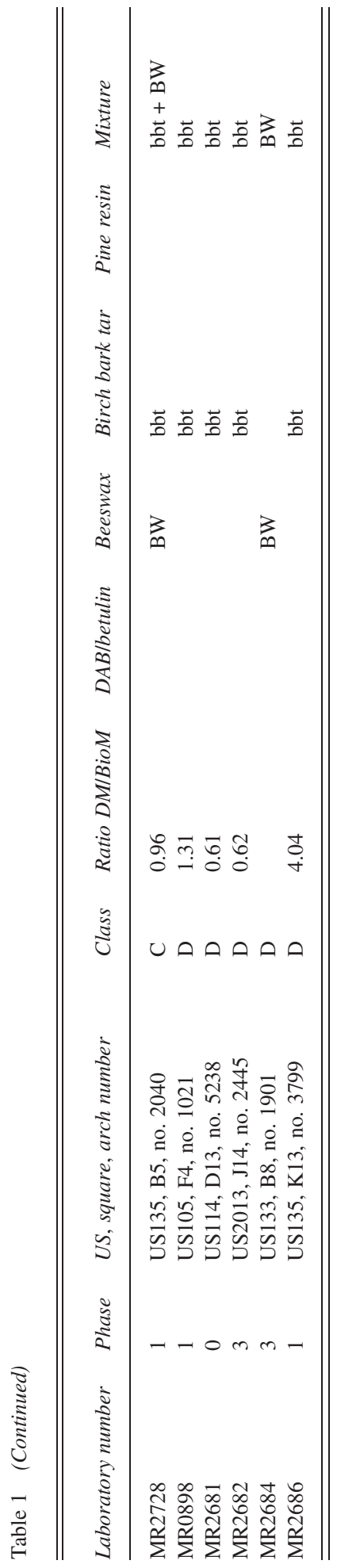

() 2015 University of Oxford, Archaeometry ••, •• (2015) ••_•• 


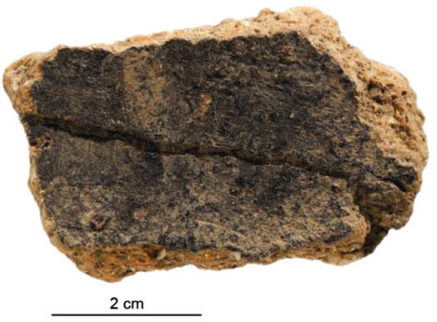

Class A : Reparation

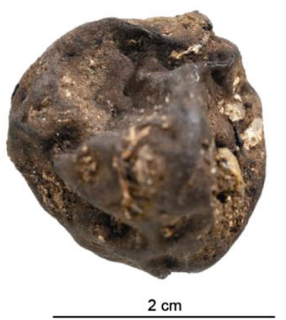

Class D: Free lumps (adhesive stocking/waste, other)
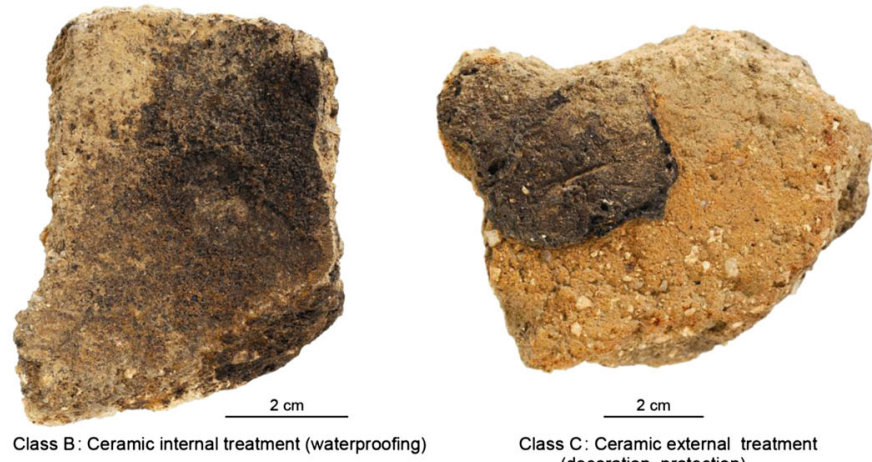

Class C: Ceramic external treatment (decoration, protection)
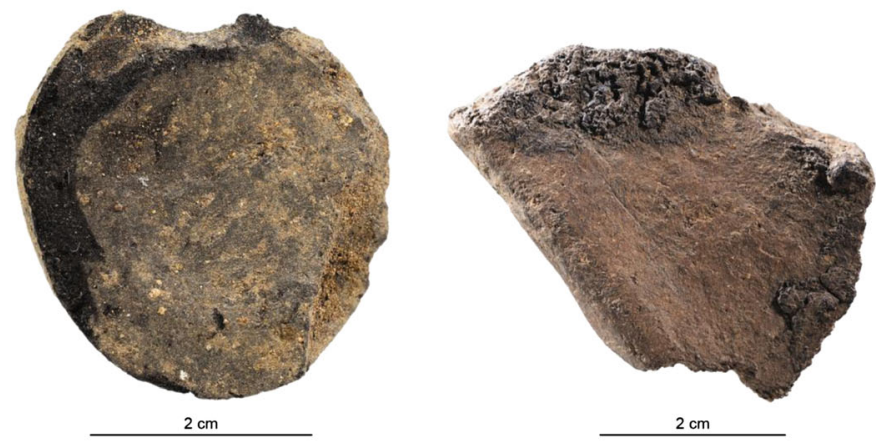

Class $\mathrm{E}$ : Ceramic content remains

Figure 2 A presentation of the different classes of samples, depending on their aspect and their localization on the sherds (@ Jean-Denys Strich, CNRS, CEPAM).

(iii) black residues on the external surface of ceramic sherds-whatever their thickness or surface expansion, they were involved in the surface treatment or decoration of the pottery (class C, 13 samples, including six from phase 0, three from phase 1 and four from phase 3).

In addition, small black flat 'cakes' (class D, five samples, including one from phase 0, two from phase 1 and two from phase 3 ) were sampled during the excavation. They were characterized by a wide variety of aspects: smooth to rough and a dark brown to black appearance. The weights of these centimetric fragments range from $0.250 \mathrm{~g}$ to $2 \mathrm{~g}$. Such remains may correspond either to adhesive storage before use or to manufacturing waste. One of them (MR2684) was chewed (indicated by the presence of tooth marks).

\section{MATERIALS AND METHODS}

In order to obtain an overall overview of the natural substances exploited at the Cuciurpula site, all the organic residues presented above were analysed using a multi-step analytical strategy (see, e.g., Regert et al. 2003). First, macro- and microscopic observations allowed for the classification of the residues according to their aspect (see the previous section). Micro-samples, the size of a pinhead, were carefully withdrawn to obtain their mass spectrometric fingerprint by 
using DI EI-MS. Depending on the presence/absence of high molecular weight compounds (wax fatty esters, triacylglycerols etc.), samples were subsequently analysed using HT GC with specific conditions (see below). For a series of samples presenting similar chromatographic profiles, HT GC-MS was performed on one representative sample in order to identify precisely the main markers previously observed by GC.

\section{Solvents, reagents and reference materials}

Solvents and chemicals of analytical grade were purchased from Sigma-Aldrich (St Quentin Fallavier, France). BSTFA, containing 1\% trimethylchlorosilane, was used for the trimethylsilylation of carboxy- and hydroxy- groups before GC and GC-MS analysis.

\section{Direct inlet electron ionization - mass spectrometry (DI EI-MS)}

For each sample, a micro-grain of matter, usually smaller than $500 \mu \mathrm{m}$ in diameter, was placed into a glass vial fixed on the probe. It was introduced into the ionization chamber of the mass spectrometer. Mass spectra were recorded using a Shimadzu QP2010 ultra mass spectrometer equipped with a quadrupole analyser. Samples were desorbed from the probe using the following temperature programme: $100^{\circ} \mathrm{C}$ for $5 \mathrm{~s} ; 100-450^{\circ} \mathrm{C}$ at $100^{\circ} \mathrm{C} \mathrm{min}^{-1} ; 450^{\circ} \mathrm{C}$ for $120 \mathrm{~s}$. Mass spectra were acquired using electron ionization at $70 \mathrm{eV}$. The mass range was scanned from $\mathrm{m} / \mathrm{z}$ 50-950 in $0.6 \mathrm{~s}$. The temperature of the ion source was fixed at $200^{\circ} \mathrm{C}$.

\section{Sample treatment before $G C$ and $G C-M S$ analyses}

After the grinding of the sample, the extraction was performed in dichloromethane (1 $\mathrm{mg}$ of sample in $1 \mathrm{ml}$ of DCM). Extraction was performed by ultrasonication for $30 \mathrm{~min}$. An aliquot $(200 \mu \mathrm{l})$ of the solution was then evaporated to dryness under a gentle stream of nitrogen. The derivatizing reagent (BSTFA, $50 \mu \mathrm{l}$ ) and catalytic reagent (pyridine, $4 \mu \mathrm{l}$ ) were added to the vial, and the mixture was placed on a heating block for $20 \mathrm{~min}$ at $40^{\circ} \mathrm{C}$. After cooling to room temperature and evaporation of the excess of BSTFA, the resulting trimethylsilyl (TMS) derivatives were diluted in dichloromethane $(50 \mu \mathrm{l})$ and analysed $(1 \mu \mathrm{l}$ for each sample) by gas chromatography.

\section{$G C$ and $G C-M S$ analyses}

The GC analyses were performed on an Agilent 7890A gas chromatograph equipped with an on-column injector. Samples determined to be free of high molecular weight components by DI EI-MS (absence of wax esters, triacylglycerols etc.) were analysed using an Agilent J\&W DB-5MS column $(30 \mathrm{~m} \times 0.25 \mathrm{~mm}$ i.d.; $0.25 \mu \mathrm{m}$ film thickness); the inlet temperature was fixed at $300^{\circ} \mathrm{C}$ and the temperature of the flame ionization detector (FID) was $340^{\circ} \mathrm{C}$. The oven temperature was ramped from $50^{\circ} \mathrm{C}$ (held isothermally for $2 \mathrm{~min}$ ) to $150^{\circ} \mathrm{C}$ at $10^{\circ} \mathrm{C} \mathrm{min}{ }^{-1}$, and then increased to $320^{\circ} \mathrm{C}$ at $4^{\circ} \mathrm{C} \mathrm{min}^{-1}$ (held isothermally for $15 \mathrm{~min}$ ). The analysis was carried out using hydrogen as carrier gas, with a constant column head pressure of 16 psi.

Samples in which wax esters were detected by means of DI EI-MS were analysed using an Agilent J\&W DB5 HT column $(15 \mathrm{~m} \times 0.32 \mathrm{~mm}$ i.d.; $0.1 \mu \mathrm{m}$ film thickness $)$. The inlet temperature was fixed at $350^{\circ} \mathrm{C}$ and that of the flame ionization detector (FID) at $340^{\circ} \mathrm{C}$. The oven temperature was ramped from $50^{\circ} \mathrm{C}$ (held isothermally for $2 \mathrm{~min}$ ) to $150^{\circ} \mathrm{C}$ at $10^{\circ} \mathrm{C} \mathrm{min}^{-1}$, and then 
increased to $320^{\circ} \mathrm{C}$ at $20^{\circ} \mathrm{C} \mathrm{min}^{-1}$ (held isothermally for $15 \mathrm{~min}$ ). The analysis was performed using hydrogen as carrier gas, with a constant pressure at the head of the column of 16 psi.

The GC-MS analyses were carried out using the same conditions as described for GC analysis (except for the use of helium as carrier gas and a split/splitless injection system, operating in the splitless mode with a purge flow of $2.0 \mathrm{ml} \mathrm{min}^{-1}$ and a split ratio of 3.0), using a Shimadzu QP2010 Ultra. Mass spectra were acquired using electron ionization at $70 \mathrm{eV}$. The mass range was scanned from $\mathrm{m} / \mathrm{z} 50-950$ in $0.6 \mathrm{~s}$. The temperatures of the ion source were fixed at $200^{\circ} \mathrm{C}$ and the transfer line at $250^{\circ} \mathrm{C}$ or $320^{\circ} \mathrm{C}$ (depending on the molecular weight of the components). The mass spectra were matched against those of authentic standards (betulin, lupeol and lupenone), by using data previously published by several authors (Binder et al. 1990; Hayek et al. 1990; Aveling and Heron 1998; Regert et al. 1998) and the NIST library.

\section{RESULTS}

Molecular biomarkers were preserved in most of the samples investigated (31 out of 36-more than $85 \%$ ). Depending on the samples, di- and triterpenoids and long-chain esters were identified.

\section{Direct inlet electron ionization - mass spectrometry (DI EI-MS)}

Most of the samples (31/36) provided an intense signal in DI EI-MS. Four main types of mass spectra were obtained (Fig. S2).

In most cases (Table S1), the mass spectrum presented peaks at $\mathrm{m} / z 189$ and 203, and a series of peaks in the $390-450 \mathrm{~m} / \mathrm{z}$ region; the peak at $\mathrm{m} / \mathrm{z} 189$ generally dominated the spectrum in the 150 $450 \mathrm{~m} / \mathrm{z}$ range (Fig. S2 (a)). These characteristics are indicative of the presence of triterpenoid components of the lupane family (Regert and Rolando 2002). The part of the spectrum for $\mathrm{m} / z>350$ corresponds to the molecular ions of the main molecular markers constitutive of the archaeological residue. The detection of ions at $\mathrm{m} / \mathrm{z} 424,426$ and 442, which are molecular ions of lupenone, lupeol and betulin respectively, provides evidence for an assemblage of biomarkers characteristic of birch bark derivatives (Regert and Rolando 2002).

The second category of mass spectra obtained (Fig. S2 (b), Table S1) combines the 'birch bark signal' and peaks at $\mathrm{m} / \mathrm{z} 257,593,621,649,677$ and 705 . These ions are typically associated with long-chain palmitic wax esters with 40, 42, 44, 46 and 48 carbon atoms, characteristic of beeswax (Regert et al. 2001; Garnier et al. 2002; Regert 2009).

The third type of mass spectrum presents the characteristic peaks of beeswax esters with peaks at $\mathrm{m} / \mathrm{z} 239$ and 285, formed by fragmentation of dehydroabietic acid, and at $\mathrm{m} / \mathrm{z} 253$ and 314, related to 7-oxodehydroabietic acid (Fig. S2 (c): Regert and Rolando 2002).

Finally, one sample (MR2684, the free lump with the tooth print) presents a specific mass spectrum with only the long-chain palmitic wax esters described above (Table S1).

\section{$G C$ and $G C-M S$ results}

To refine the global information acquired by DI EI-MS regarding the nature, degree of transformation and alteration, the archaeological samples were then analysed using GC and GC-MS. For the five samples that did not provide any signal in DI EI-MS, no molecule was observed in gas chromatography, confirming the absence of lipids in the residues. This may result from the carbonization of the remains. Thin black deposits on the outer pottery surface may also be due to a besmoking phenomenon, which can be correlated with the total absence of lipid matter 
residues (class C) on the outside surface of the ceramics (samples MR2706, MR2673, MR2714, MR2718 and MR2727).

In most of the samples (25/36; i.e., 69\%-see Table S1 and Fig. S3), an association of the following triterpenoid constituents was detected (Fig. S3): lupa-2,20(29)-diene; lupa-2,20(29)-dien28-ol*; allobetul-2-ene*; lupenone; lupeol*; erythrodiol; betulone*; 3-oxoallobetulane; betulin*; and allobetulin*. The constituents marked with an asterisk were present in all of the samples containing triterpenoids. Betulin and lupeol are known to be the main biomarkers of birch bark from Betula pendula Roth (=B. verrucosa Ehrh. = B. alba L. p.p.), which also contains lesser amounts of lupenone and erythrodiol (Aveling and Heron 1998). Any other triterpenoids are from the chemical degradation of native biomarkers, by either a heating process that transforms birch bark into tar or post-depositional alteration effects, as summarized in Figure S4 (Charters et al. 1993; Aveling and Heron 1998; Regert et al. 1998; Regert 2004). This molecular signature is thus characteristic of birch bark tar. The relative proportions of the different molecular markers differ from one sample to another. In order to assess the degree of transformation of birch bark, the ratio between the degraded markers (lupa-2,20(29)-diene, lupa-2,20(29)-dien-28-ol, allobetul-2-ene) and the biomarkers (lupeol and betulin) was calculated (Table S1: Regert et al. 2003). Although it was not possible to elicit general trends on the degree of transformation or degradation of birch bark tar, it appears that four of the samples presented a high degree of degradation (samples MR2703, MR2686, MR272int and MR2672ext: see below).

In addition to molecular markers of birch bark tar, some samples contained long-chain palmitic esters with an even number of carbon atoms from $\mathrm{C}_{40}$ to $\mathrm{C}_{50}$ and saturated long-chain even-numbered fatty acids $\left(\mathrm{C}_{22: 0}\right.$ to $\left.\mathrm{C}_{28: 0}\right)$ characteristic of beeswax (Evershed et al. 1997; Regert et al. 2001; Garnier et al. 2002; Evershed and Dudd 2003; see also Fig. 3). Their distribution is not in perfect agreement with that of raw contemporary beeswax (due to loss of the esters with the shortest chains). As already mentioned in the literature, this may be attributed to a process of preferential hydrolysis of shorter-chain esters (Regert et al. 2001; Lattuati-Derieux

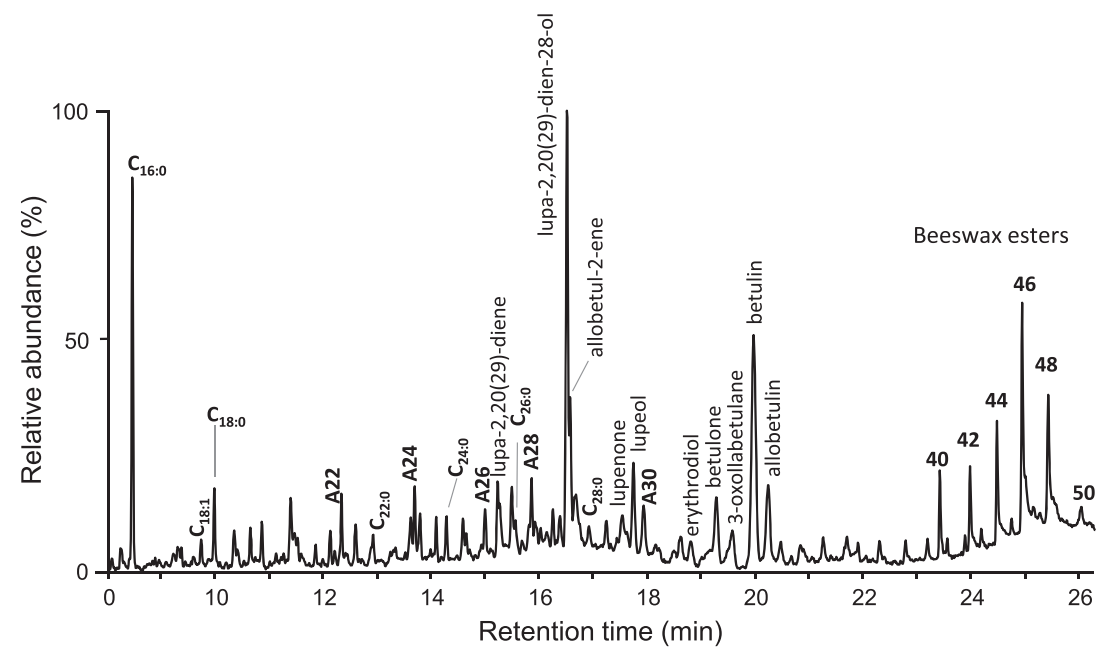

Figure 3 A chromatogram of sample MR0909, showing the presence of triterpenoid markers of birch bark tar associated with molecular constituents of beeswax. Cx:y, fatty acid with $x$ carbon atoms and y unsaturations; Ax, $n$-alcohol with $x$ carbon atoms. 
et al. 2008). This hypothesis is confirmed by the presence of palmitic acid and even-numbered $n$-alcohols from 22 to 30 carbon atoms (Fig. 3). In one of the free lumps with a tooth print (MR2684), beeswax was also identified as a pure material.

Finally, diterpenoid constituents were clearly identified in seven samples, either in association with beeswax markers (five samples of class B; Table S1), with birch bark tar (one sample of class A; MR2675) or with both (one sample of class C; MR2704). Traces of diterpenoids were also detected in association with birch bark tar or with beeswax in four samples of class A (MR0907, MR2685, MR0909 and MR2687), one sample of class B (MR0908int) and two samples of class C (MR2680ext and MR0908ext). For those seven samples, the low amount of diterpenoid markers (usually the unique presence of dehydroabietic acid = DHA) makes it difficult to identify an intentional or fortuitous addition (DHA area/betulin area $<0.1$ ).

For samples where diterpenoids were detected in noticeable amounts, the main constituents are dehydroabiectic acid and 7-oxodehydroabietic. Abieta-6,8,11,13-tetraen-18-oic acid, 7-hydroxy dehydroabietic acid and 15-hydroxy-7-oxo dehydroabietic were also identified in a

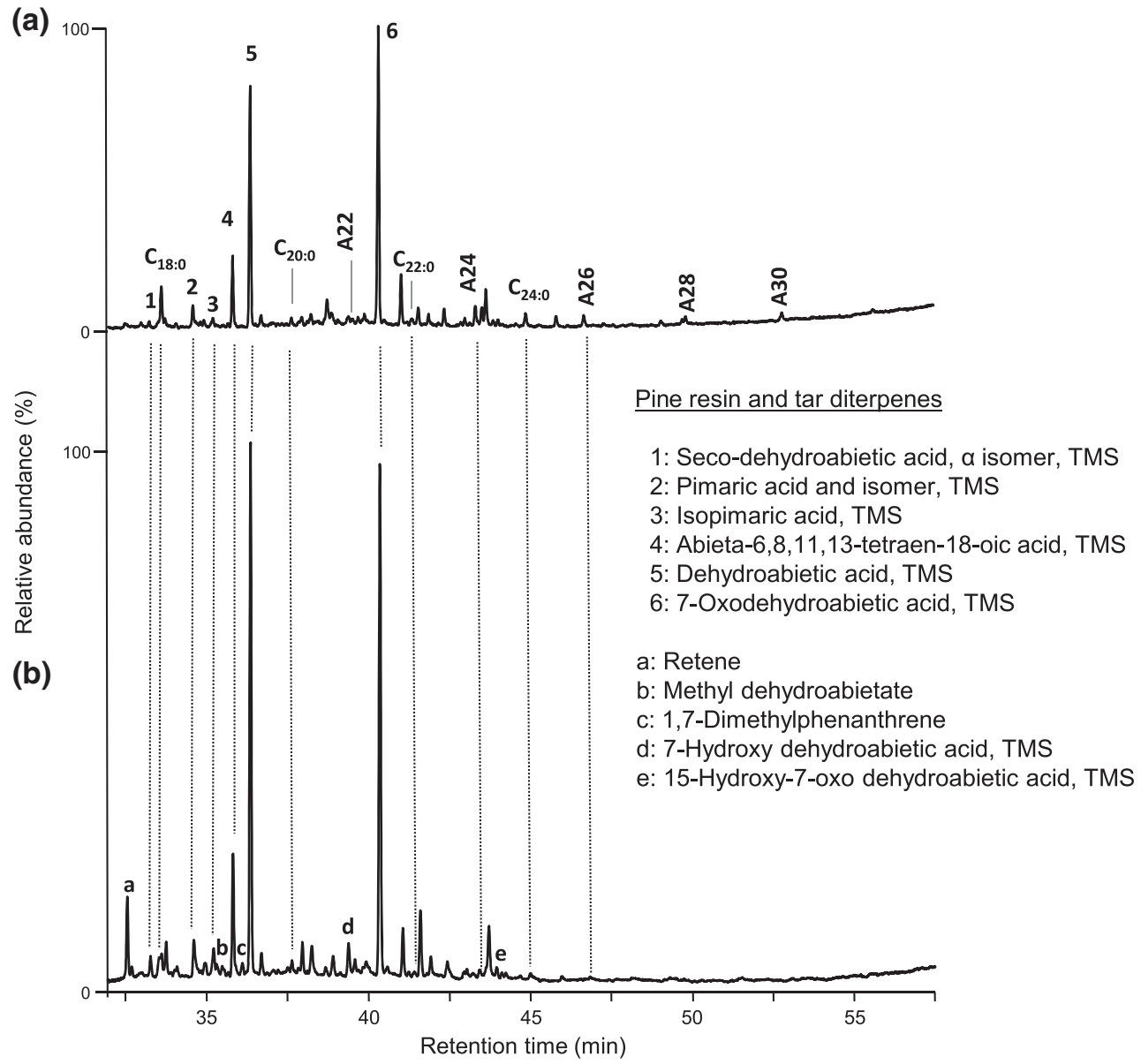

Figure 4 A chromatogram of pine resin (A: MR2708) and heated pine resin/tar (B: MR2720) with markers of beeswax. Cx:y, fatty acid; Ax, straight-chain alcohol with $x$ carbon atoms. 
few samples (Fig. 4). These markers, formed by direct or indirect degradation of abietic acid (Fig. S5), are characteristic of resin or tar obtained from Pinaceae (Chiavari et al. 2002; Osete-Cortina and Doménech-Carbó 2005; Helwig et al. 2008; Steigenberger and Herm 2011). In addition, $\alpha$ - and $\beta$-seco-dehydroabietic acids, pimaric acid-sometimes present in noticeable amounts-and isopimaric acid were identified in five samples. Their presence is characteristic of a Pinus origin (Helwig et al. 2008). Whether the diterpenoid substances correspond to a tar, an oxidized resin or a resin is quite difficult to determine. However, the presence of phenanthrene derivatives (1,7-dimethylphenanthrene and retene) in the two samples from phase 3 (MR2720 and MR2721) suggests the use of a highly degraded material, probably obtained by strong heating. This led us to think that we were in the presence of a pine tar (Reunanen et al. 1996) and the identification of methyl dehydroabietate confirmed this hypothesis (Egenberg et al. 2002; Hjulström et al. 2006). For the other samples, the lower degree of degradation is interpreted as a result of the use of pine resin, probably heated.

These results highlight a complex system of the acquisition and use of plant resins and tars in association with beeswax that has never previously been recorded for the Iron Age. This opens up new avenues for understanding technical systems, the management of natural resources and intercultural relationships, as discussed below.

\section{DISCUSSION}

The results obtained from amorphous residues of the Cuciurpula site are of high importance for assessing the production of plant exudates and tars during the Iron Age in the Mediterranean area. Despite the southern latitude of the site $\left(41.76491^{\circ} \mathrm{S}\right)$, birch bark tar has been widely used at this site, since it was detected in almost $70 \%$ of the samples analysed. This result raises the question of the Betula bark procurement in an environment where birch is not a priori a widespread species. To address this question, two ranges of data may be considered: the first anthracological data from Cuciurpula (Pêche-Quilichini et al. 2010) and the palynological data from lake sequences that provide an overview of the vegetation and its evolution in Corsica during the Holocene (Reille et al. 1999). A preliminary charcoal analysis was focused on carbonized deposits from a domestic fireplace located in structure 1 (US 105). The analysis of 400 charcoals led to the identification of 19 taxa corresponding to a minimum of 15 different species or genera (Pêche-Quilichini et al. 2010). In accordance with the geographical location of Cuciurpula (1000 $\mathrm{m}$ a.s.l.), the anthracological spectrum suggests a fuelwood supply mainly originating from the mesomediterranean and supramediterranean levels and, to a lesser extent, from the mountain and subalpine levels (Pêche-Quilichini et al. 2010). This result is consistent with domestic fuelwood supply practices based on a non-selective use of wood species available in the environment. This first anthracological corpus characterizes the woody vegetation in the wood supply area of the inhabitants of structure 1, which extended in the vicinity of Cuciurpula mainly on the south-facing slope of the Punta di Cuciurpula (Fig. 5). The woody landscape perceived by anthracology was rather different from the current one: quite open, it was dominated by a honey plant, the heath (Erica cf. arborea and Erica account for 60\%), associated with the strawberry tree (Arbutus unedo; 13.5\%), which is typical of the higher mesomediterranean south-facing slope. The charcoal spectrum also revealed the presence of arborescent taxa typical of the supramediterranean level south-facing slope; that is, deciduous oak (cf., Quercus pubescens), a Scots-type pine (probably Corsican pine) and evergreen oak (Quercus ilex/coccifera), which represent around $13 \%$ of the relative frequencies. These data restore a mosaic landscape with an alternating sequence of shrublands, open spaces resulting 


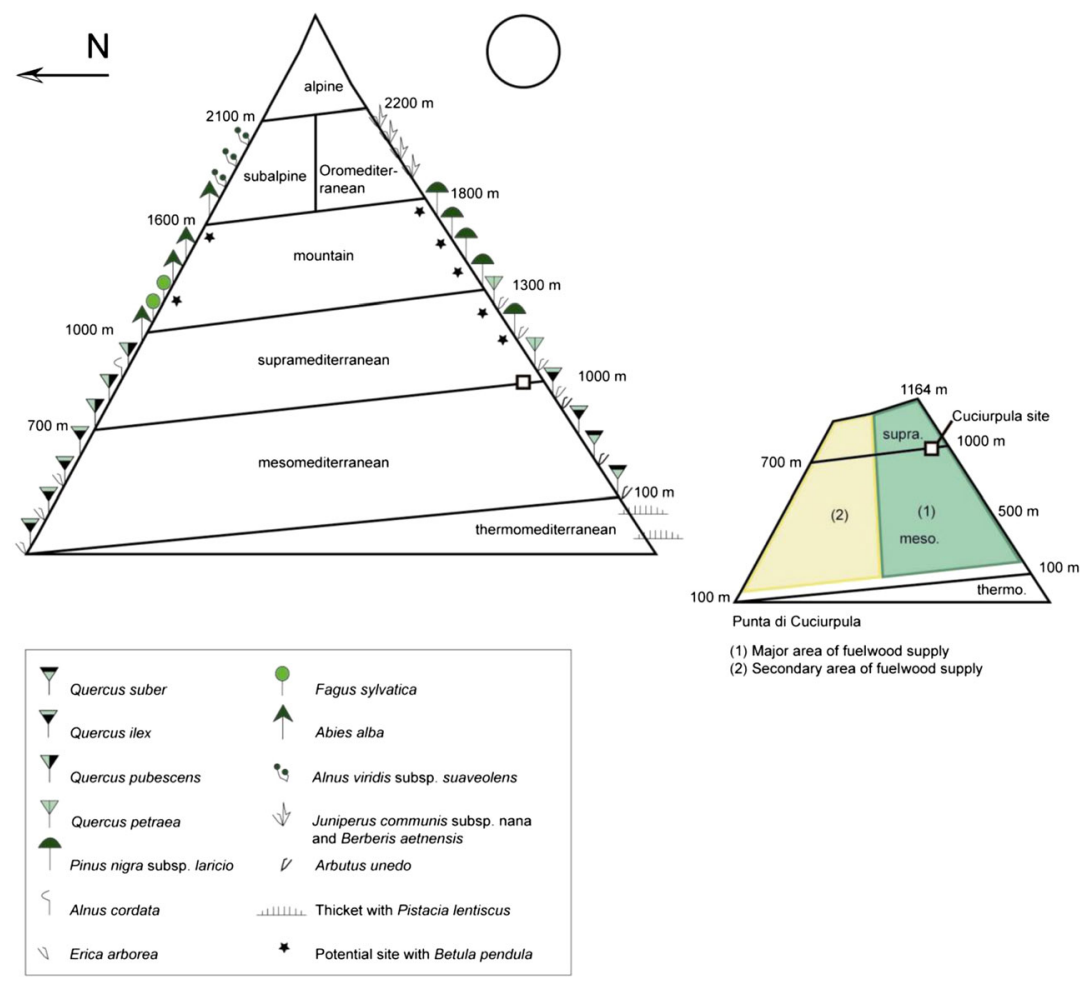

Figure 5 The integration of Cuciurpula within the vegetation levels of Punta di Cuciurpula and the Corsica massif. The current vegetation in Corsica is according to Gamisans (1981, 1991).

from agro-pastoral activities, and woodland areas developed at a much higher altitude. Betula is not represented in the anthracological corpus; it may be inferred that it was extremely inaccessible in the wood supply area and/or that it was not used as a domestic fuelwood. Betula pendula is the only Betula species currently present in Corsica (Reille et al. 1999). It grows on fresh sites and in open woodlands, with deciduous Quercus and Corsican pine in the supramediterranean level and with Corsican pine, Fagus sylvatica (beech) and Abies alba (fir) in the mountain level. The presence of supramediterranean taxa in the anthracological spectrum-that is, Ulmus (elm) or Fraxinus (ash tree)—suggests that the inhabitants of structure 1 were attending sites where Betula pendula was potentially present. Thus birch bark was probably not imported to Corsica but resulted from a local harvest. The absence of Betula wood in the anthracological spectrum and the wide use of its bark for making tar reflect specific management of environment availabilities for making plant products. This interpretation involves the implementation of a specific technical process to collect bark, which begins in the forest. It requires specific knowledge and know-how to choose the trees, depending on their age, the bark quality, the trunk diameter and the harvesting season (in order to avoid killing trees). The two other materials identified-pine resin/tar and beeswax - are probably also local products, supplied, respectively, by Corsican pine and honeybees that had the opportunity to forage on Erica.

The second point of the discussion concerns the uses of the materials identified. No clear correlation could be established between them and their location or role on the vessel (adhesive 
product, or residue on the inside or outside part of the pottery), or their attribution to archaeological levels. However, some general trends can be elicited.

Birch bark tar was used in all of the 10 mending adhesives studied, in half of the cases as a pure material (MR2677, MR280int, MR0899, MR2674 and MR2678). In one sample (MR2675), it is associated with pine resin derivative and in four others (MR0907, MR2685, MR0909 and MR2687) with traces of dehydroabietic acid. The last two samples also contain beeswax makers. Four out of five flat 'cakes' only contain birch bark tar. The only one that is different (beeswax) is marked by a tooth impression. The chewing of birch bark is attested since Mesolithic times, probably for its medicinal properties (Evans and Heron 1993; Aveling and Heron 1999; Kjellström et al. 2010), but this is the first report of chewing beeswax. However, beeswax was used as a dental filling on a Neolithic human tooth (Bernardini et al. 2012); the sample from Cuciurpula could be a second example that illustrates the role of beeswax in dental care.

Finally, the association of pine resin/tar and beeswax was only encountered on residues covering the inner surface of the pottery (five samples: MR2708, MR2692, MR2697, MR2720 and MR2721), while the combination of birch bark tar and beeswax was only found on samples from the outside surface of the pottery (three samples: MR2676, MR2679 and MR2728).

These observations give rise to several functional interpretations. The presence of small lumps of birch bark tar, already described at other sites (Binder et al. 1990; Aveling and Heron 1998), is probably linked to the production or storage of tar. The lumps may be waste residues from production or use (such as MR2686, which presents a high degree of degradation, with a $\mathrm{DM} / \mathrm{BM}$ ratio at 4; Table S1): they can also correspond to a reserve of raw material for future use. The first hypothesis is unlikely: in practice, the production of birch bark tar is carried out in an uninhabited place, because it necessitates specific fireplaces and produces strong vapours. Furthermore, the flat lumps, only a few millimetres thick, may characterize residues of birch bark tar storage in the village for ceramic mending. Finally, three samples of pure birch bark tar (MR2703, MR2672int and MR2672ext) identified in relation to a ceramic vessel were badly degraded (DM/BM ratio about 4; Table S1). The location of MR2703 at the base of a ceramic vessel (at the junction of the body and the base) and the boiling aspect of MR2672int and MR2672ext led us think that this pottery was dedicated to reheating birch bark tar before use. All these clues indicate that birch bark tar was probably produced outside the village and conditioned as small flat cakes. They could be reheated in ceramic vessels before being applied on pottery either as an adhesive, a decorative piece or a waterproofing agent.

The association of birch bark tar with beeswax and/or pine resin in reparation adhesives may result from the need to obtain adhesives with various properties. In particular, beeswax allows for the production of a shiny material with interesting plastic properties that could have been specifically manufactured. The other hypothesis is that ceramics that had contained, or had been waterproofed with, beeswax and/or resin were subsequently repaired with birch bark tar. This assumption is reinforced by the presence of a mixture of pine resin and beeswax that was only identified in the inner parts of the pottery. The simultaneous presence of pine resin, beeswax and birch bark tar may also be due to various uses or reuses of the vessels.

A last use for these materials is their role in the decoration of vessels. Indeed, five sherds present more or less large bands of black organic matter and two others present thin black layers on their outside surface (Fig. S6). All of them contain birch bark tar, in most cases (five out of seven) mixed with beeswax.

Besides environmental and functional considerations, these results raise fundamental questions about the cultural practices of Cuciurpula's inhabitants. During the Neolithic in continental Europe, birch bark tar is largely used either as an hafting adhesive for projectile points or 
for repairing ceramic vessels (Binder et al. 1990; Evans and Heron 1993; Regert et al. 1998; Weiner 1999; Urem-Kotsou et al. 2002; Regert 2004; Stern et al. 2006; Lucquin et al. 2007; Regert and Mirabaud 2014). Very few data are available on adhesive or waterproofing substances used during the first Iron Age in Europe. Birch bark tar has been exploited to the north of the Alpine chain and in the Balkans for a variety of ceramic treatments as decoration or reparation (Hayek et al. 1990, 1991; Sauter et al. 2002; Doracic et al. 2012). During the sixth and seventh centuries BC, pine pitch was used by the Etruscans for caulking their shipping fleet (Robinson et al. 1987). Pine tar or resin mixed with beeswax was also used to waterproof amphora at the Etruscan site of La Castellina. From the sixth century BC, the Greeks employed pine exudates for the same purpose (Connan and Nissenbaum 2003). In other words, the autochthonous populations of the Hallstatt culture used birch bark tar, whereas pine pitch was the waterproofing agent in use in the classical world. Besides, if ceramic vessels were repaired with birch bark tar adhesives during the first Iron Age in Corsica, this practice is not documented in Sardinia, where pottery was repaired with lead staples (Antona et al. 2010). It thus clearly appears that various waterproofing and decorating techniques for ceramic containers were in use in the western Mediterranean area during the first Iron Age. These regional particularities may result from a local combination of the shared pre-Roman cultural background (Garcia 2012) and sporadic interactions with populations that were trading in the western Mediterranean Sea. In particular, the production and use of birch bark tar may be related to continental traditions that could have survived in the Corsican environment, where birch is available, as opposed to Sardinia, where this species is unknown. Whether the know-how about making birch bark tar was introduced into Corsica during the Neolithic or in protohistory is still difficult to assess. The use of birch bark tar at Neolithic sites located in the south-east of France (Binder et al. 1990; Regert et al. 2000) may have been transferred to Corsica in this period. On the other hand, this tradition could have been introduced during the Final Bronze Age, a period of strong transfers of cultural influence between the continent and Corsica (Pêche-Quilichini 2012a). Nevertheless, this last hypothesis still has to be tested, since there is only one example of birch bark tar exploitation in northern Italy during the Final Bronze Age (Chelidonio 1997).

In contrast, pine resin was scarcely used before the development of the Etruscan civilization. In the western Mediterranean area, only one example has been found, at the Final Bronze Age site of La Fangade (Regert 2004). Consequently, autochthonous populations were able either to exploit pine resin without any other cultural influence or, more probably, they adopted it after contacts, even sporadic ones, with other populations. Such contacts, whether direct or not, are attested by several bead fragments in blue glass, originating from the Near East. The archaeological context of this bead is still uncertain, but it was probably part of a burial (Cuciurpula, shelter 2). Exogenous artefacts (such as a fibula, for example) are also identified more significantly in the north of the island and integrate this part of Corsica into the Mediterranean traffic, and especially with the Etruscan civilization (Lechenault 2011). The combination of three organic materialsbirch bark tar, pine resin and beeswax - for the reparation of pottery and for the treatment of their inner surface and decoration is unique in the history of ceramic vessels. It illustrates a cultural syncretism characterized by multiple and original technical choices made by the populations of the first Iron Age in Corsica.

\section{CONCLUSIONS}

Until recently, most of the information available on the Iron Age populations of Corsica came from funeral sites, providing an incomplete and biased panorama of the cultural features of 
these protohistoric societies. The data presented here illustrate the strength and the potential of research focused on domestic contexts that have been largely underestimated up to now (Pêche-Quilichini 2012a). They fill a gap in our knowledge on the technical and cultural traditions of the Iron Age just before Greek colonization. They show that the natural resources (i.e., beehive products, trees and their derivatives) upon which the exercise of power of the newcomers was based were already being managed by the autochthonous populations. The use of natural biological resources with plant and animal origins may possibly be related to ancient knowledge dating back to one of the prehistoric colonization episodes of Corsica-particularly for birch bark tar, which has a long history on the continent. The absence of Betula in the charcoal assemblage from Cuciurpula's structure 1 tends to show that birch bark was specifically collected to make tar, and suggests the specialized management of this taxon in the Cuciurpula area. In addition, it assumes that the trees were kept alive after the bark harvest. The use of pine resin may have been developed on the island without any other cultural influence, but it may also result from early contacts with traders who travelled across the Mediterranean Sea during this period. Finally, beeswax is the most ancient clue to the exploitation of beehive products in Corsica. It is not possible to determine whether it was obtained from wild or domestic beehives. Nevertheless, several archaeological data have shown that domestic beehives were in use during the Iron Age in most of the Mediterranean basin, from the Near East (Mazar et al. 2008) to Spain (Bonet Rosado and Mata Parreño, 1997). It is therefore possible to propose that beeswax and honey have been produced in domestic beehives on the island since at least the first Iron Age. But this hypothesis must be reinforced with other archaeological and chemical data in the years to come.

These substances were used for various purposes, in specific ways. Birch bark tar and pine resin seem to play different roles in the treatment of ceramic vessels: pine resin was mostly reserved for waterproofing the inner part of the vessels, while birch bark tar was the most important ingredient for adhesive making in order to repair ceramic vessels. As usual, the function of beeswax is more difficult to determine: it may have been used as a waterproofing agent in association with pine resin, but its properties were also probably employed to provide an adhesive with birch bark tar, which has a certain plasticity. Also, beeswax provides a shiny aspect to the decorative black substances applied as bands on the outside surface of ceramic vessels.

All these results shed new light on the technical and cultural practices of the Iron Age societies of Corsica. They provide new evidence for their know-how, the way in which they used the natural resources of their environment and the chronology of exploitation of fragile resources, not often preserved in the archaeological record due to the high sensitivity to natural processes of alteration. In the future, particular attention should be paid to such remains that can obviously be preserved, even in sedimentary contexts (acid sediments from granitic basement) a priori not suitable for their preservation.

\section{ACKNOWLEDGEMENTS}

The authors are very grateful to the ANR (Agence Nationale de la Recherche) and for its financial support of the research programme EXSUDARCH, dedicated to the chemistry, manufacture and use of plant exudates and tars. The results presented here make up part of the Ph.D. studies of Maxime Rageot, funded by the CNRS and the Région PACA, and supported by the University of Nice Sophia Antipolis. The French Ministère de la Culture et la Communication also contributed to this doctoral research. We are grateful to these institutions for their support. We sincerely thank Arnaud Mazuy for his technical expertise in GC and GC-MS. We are also most grateful to 
Dr Isabelle Théry-Parisot, Dr Sylvie Beyries and Dr Claire Delhon for fruitful discussions and help for specific bibliographical references related to the vegetal history of Corsica within the ANR EXSUDARCH.

\section{REFERENCES}

Antona, A., Corro, D. M., and Puggioni, S., 2010, Spazi di lavoro e attività produttive nel villaggio nuragico La Prisgiona in località Capichera (Arzachena), in L'Africa romana XVIII: i luoghi e le forme dei mestieri e della produzione nelle province africane. Atti del XVIII convegno di studio, Olbia, 11-14 dicembre 2008 (eds. M. Milanese, P. Ruggeri and C. Vismara), 1713-34, Carocci editore, Rome.

Aveling, E. M., and Heron, C., 1998, Identification of birch bark tar at the Mesolithic site of Star Carr, Ancient Biomolecules, 2, 69-80.

Aveling, E. M., and Heron, C., 1999, Chewing tar in the early Holocene: an archaeological and ethnographic evaluation, Antiquity, 73(281), 579-84.

Bernardini, F., Tuniz, C., Coppa, A., Mancini, L., Dreossi, D., Eichert, D., Turco, G., Biasotto, M., Terrasi, F., De Cesare, N., Hua, Q., and Levchenko, V., 2012, Beeswax as dental filling on a Neolithic human tooth, PLoS ONE, 7(9), e44904.

Binder, D., Bourgeois, G., Benoist, F., and Vitry, C., 1990, Identification de brai de bouleau (Betula) dans le néolithique de Giribaldi (Nice, France) par la spectrométrie de masse, Revue d'Archéométrie, 14, 37-42.

Bonet Rosado, H., and Mata Parreño, C., 1997, The archaeology of beekeeping in pre-Roman Iberia, Journal of Mediterranean Archaeology, 10(1), 33-47.

Charters, S., Evershed, R. P., Goad, L. J., Heron, C., and Blinkhorn, P., 1993, Identification of an adhesive used to repair a Roman jar, Archaeometry, 35, 91-101.

Chelidonio, G., 1997, Preliminary approach to birch tar use in Cà Nove di Cavaion (Verona-I) Bronze Age site, in Proceedings of the First International Symposium on Wood Tar and Pitch (eds. W. Brzezinski, and W. Piotrowski), 45-50, State Archaeological Museum, Warsaw.

Chiavari, G., Fabbri, D., and Prati, S., 2002, Characterisation of natural resins by pyrolysis-silylation, Chromatographia, 55(9-10), 611-16.

Connan, J., and Nissenbaum, A., 2003, Conifer tar on the keel and hull planking of the Ma'agan Mikhael Ship (Israel, 5th century $\mathrm{BC}$ ): identification and comparison with natural products and artefacts employed in boat construction, Journal of Archaeological Science, 30, 709019.

Doracic, D., Pausewein, R.-R., Sanchez, E. G., and Potrebica, H., 2012, Birch tar glue on early Iron Age vessels from Kaptol-Gradci, Croatia, in Second International Symposium on Wood Tar and Pitch, Archaeological Museum in Biskupin and Arbeitsgruppe Teerschwele im Museumsdorf Düppel, Berlin, Archaeological Museum in Biskupin, Poland.

Egenberg, I. M., Aasen, J. A. B., Holtekjølen, A. K., and Lundanes, E., 2002, Characterisation of traditionally kiln produced pine tar by gas chromatography - mass spectrometry, Journal of Analytical and Applied Pyrolysis, 62, 143-55.

Evans, K., and Heron, C., 1993, Glue, disinfectant and chewing gum: natural products chemistry in archaeology, Chemistry and Industry, 21 June, 446-9.

Evershed, R. P., and Dudd, S. N., 2003, New chemical evidence for the use of combed ware pottery vessels as beehives in ancient Greece, Journal of Archaeological Science, 30, 1-12.

Evershed, R. P., Vaughan, S. J., Dudd, S. N., and Soles, J. S., 1997, Fuel for thought? Beeswax in lamps and conical cups from Late Minoan Crete, Antiquity, 71, 979-85.

Gamisans, J., 1981, La montagne corse: une montagne subméditerranéenne marquée par l'endémisme, Anales del Jardin Botánico de Madrid, 37(2), 315-19.

Gamisans, J., 1991, La végétation de la Corse in compléments au prodrome de la flore Corse, annexe 2, Conservatoire et Jardin botaniques, Genève.

Garcia, D., 2012, Préface, in L'âge du Fer en Corse-acquis et perspectives, 5-6, Actes de la Table-Ronde de Serra-diScopamena, Serra-di-Scopamena.

Garnier, N., Cren-Olivé, C., Rolando, C., and Regert, M., 2002, Characterization of archaeological beeswax by electron ionization and electrospray ionization mass spectrometry, Analytical Chemistry, 74(19), 4868-77.

Hayek, E. W. H., Krenmayr, P., Lohninger, H., Jordi, U., Moche, W., and Sauter, F., 1990, Identification of archaeological and recent wood tar pitches using gas chromatography/mass spectrometry and pattern recognition, Analytical Chemistry, 62, 2038-43.

Hayek, E. W. H., Krenmayr, P., Lohninger, H., Jordi, U., Sauter, F., and Moche, W., 1991, GC/MS and chemometrics in archaeometry: investigation of glue on copper-age arrowheads, Fresenius Journal of Analytical Chemistry, 340, 153-6. 
Helwig, K., Monahan, V., and Poulin, J., 2008, The identification of hafting adhesive on a slotted antler point from a southwest Yukon ice patch, American Antiquity, 73, 279-88.

Hjulström, B., Isaksson, S., and Hennius, A., 2006, Organic geochemical evidence for pine tar production in middle eastern Sweden during the Roman Iron Age, Journal of Archaeological Science, 33, 283-94.

Jehasse, O., 2003, Corsica Classica: la Corse dans les textes anciens, VII siècle av. J.-C.-an 1000, La Marge éditions, Ajaccio.

Kjellström, A., Nordquist, B., Snäll, A., and Welinder, S., 2010, Capturing the moment: chewing today and 10000 years ago, AmS-Skrifter, 23, 53-61.

Lattuati-Derieux, A., Thao, S., Langlois, J., and Regert, M., 2008, First results on headspace - solid phase microextraction - gas chromatography/mass spectrometry of volatile organic compounds emitted by wax objects in museums, Journal of Chromatography A, 1187, 239-49.

Lechenault, M., 2011, Les trafics dans les îles de Méditerranée centrale et occidentale au premier âge du Fer: la corse des échanges, Universités de Lyon 2 et de Rome I.

Lucquin, A., March, R. J., and Cassen, S., 2007, Analysis of adhering organic residues of two 'coupes-à-socles' from the Neolithic funerary site 'La Hougue Bie' in Jersey: evidences of birch bark tar utilisation, Journal of Archaeological Science, 34, 704-10.

Mazar, A., Namdar, D., Panitz-Cohen, N., Neumann, R., and Weiner, S., 2008, Iron Age beehives at Tel Rehov in the Jordan valley, Antiquity, 82(317), 629-39.

Osete-Cortina, L., and Doménech-Carbó, M. T., 2005, Analytical characterization of diterpenoid resins present in pictorial varnishes using pyrolysis - gas chromatography - mass spectrometry with on line trimethylsilylation, Journal of Chromatography A, 1065(2), 265-78.

Pêche-Quilichini, K., 2012a, Le Bronze final et le premier âge du Fer de la Corse: chronologie, production céralique et espaces culturels, Acta Archaeologica, 83, 203-23.

Pêche-Quilichini, K., 2012b, Les fouilles de Cuciurpula: la structure 1, in L'âge du Fer en Corse-acquis et perspectives, 35-126, Actes de la Table-Ronde de Serra-di-Scopamena.

Pêche-Quilichini, K., Py, V., and Regert, M., 2010, Exploitation des matières premières végétales en contexte insulaire montagnard: l'exemple de l'habitat du premièr âge du Fer de Cuciurpula (Serra-di-Scopamène et Sorbollano, Corse-du-sud), in Des hommes et des plantes: exploitation du milieu et gestion des ressources végétales de la préhistoire à nos jours. XXX rencontres internationales d'archéologie et d'histoire d'Antibes (eds. C. Delhon, I. Théry-Parisot and S. Thiébault), Editions APDCA, Antibes.

Regert, M., 2004, Investigating the history of prehistoric glues by gas chromatography - mass spectrometry, Journal of Separation Science, 27, 244-54.

Regert, M., 2007, Elucidating pottery function using a multi-step analytical methodology combining infrared spectroscopy, mass spectrometry and chromatographic procedures, in Theory and practice of archaeological residue analysis (eds. H. Barnard and J. Eerkens), 61-76, British Archaeological Reports, International Series, 1650, Archaeopress, Oxford.

Regert, M., 2009, Direct mass spectrometry to characterise lipid materials, in Organic mass spectrometry in art and archaeology (eds. M.-P. Colombini and F. Modugno), 97-129, Chichester, Wiley.

Regert, M., and Mirabaud, S., 2014, Substances naturelles exploitées sur les sites de Chalain et Clairvaux: nature et fonction des matériaux organiques amorphes, in Entre archéologie et écologie, une préhistoire de tous les milieux: mélanges offerts à Pierre Pétrequin (eds. R.-M. Arbogast and A. Greffier-Richard), Presses Uni Franche Comté, Besançon.

Regert, M., and Rolando, C., 2002, Identification of archaeological adhesives using direct inlet electron ionization mass spectrometry, Analytical Chemistry, 74(5), 965-75.

Regert, M., Colinart, S., Degrand, L., and Decavallas, O., 2001, Chemical alteration and use of beeswax through time: accelerated ageing test and analysis of archaeological samples from various environmental contexts, Archaeometry, 43, 549-69.

Regert, M., Garnier, N., Binder, D., and Pétrequin, P., 2000, Les adhésifs néolithiques: quels matériaux utilisés, quelles techniques de production dans quel context social ? L'exemple des adhésifs des sites de Giribaldi et de Chalain, in Arts du feu et productions artisanales: $X X^{e}$ rencontres internationales d'archéologie et d'histoire (eds. P. Pétrequin, $\mathrm{Ph}$. Fluzin, J. Thiriot and P. Benoit), Editions APDCA, Antibes.

Regert, M., Vacher, S., Moulherat, C., and Decavallas, O., 2003, Adhesive production and pottery function during the Iron Age at the site of Grand Aunay (Sarthe, France), Archaeometry, 45, 101-20.

Regert, M., Delacotte, J.-M., Menu, M., Pétrequin, P., and Rolando, C., 1998, Identification of Neolithic hafting adhesives from two lake dwellings at Chalain (Jura, France), Ancient Biomolecules, 2, 81-96.

Reille, M., Gamisans, J., Andrieu-Ponel, V., and de Beaulieu, J.-L., 1999, The Holocene at Lac de Creno, Corsica, France: a key site for the whole island, New Phytologist, 141, 291-307.

Reunanen, M., Ekman, R., and Hafizoglu, H., 1996, Composition of tars from softwoods and birch, Holzforschung, 50(2), 118-20. 
Robinson, N., Evershed, R. P., Higgs, W. J., Jerman, K., and Eglinton, G., 1987, Proof of a pine wood origin for pitch from Tudor (Mary Rose) and Etruscan shipwrecks: application of analytical organic chemistry in archaeology, Analyst, 112, 637-44.

Sauter, F., Graf, A., Hametner, C., Fröhlich, J., Neugebauer, J.-W., and Preinfalk, F., 2002, Studies in organic archaeometry IV: analysis of an organic agglutinant used to fix Iron-age clay figurines to their base, ARKIVOC, i, 35-9.

Steigenberger, G., and Herm, C., 2011, Natural resins and balsams from an eighteenth-century pharmaceutical collection analysed by gas chromatography/mass spectrometry, Analytical and Bioanalytical Chemistry, 401(6), 1771-84.

Stern, B., Clelland, S. J., Nordby, C. C., and Urem-Kotsou, D., 2006, Bulk stable light isotopic ratios in archaeological birch bark tars, Applied Geochemistry, 21, 1668-73.

Urem-Kotsou, D., Stern, B., Heron, C., and Kotsakis, K., 2002, Birch bark tar at Neolithic Makriyalos, Greece, Antiquity, 76, 962-7.

Weiner, J., 1999, European pre- and protohistoric tar and pitch: a contribution to the history of research 1720-1999, Acta Archaeometrica, 1, 1-109.

\section{SUPPORTING INFORMATION}

Additional Supplementary material may be found in the online version of this paper on the publisher's website:

Figure S1 Location of the amorphous organic residues within the stratigraphic units (SU). Figure S2 The different fingerprints from Cuciurpula samples by DI EI-MS: a) mass spectrum characterised by peaks of triterpenoids from the lupane family obtained on sample MR2677; b) mass spectrum with a signal typical of a mixture of birch bark derivative and beeswax (sample MR2676); c) mass spectral fingerprint giving evidence of the association of beeswax with a diterpenoid substance (sample MR2692).

Figure S3 Chromatogram of birch bark tar (sample MR2681). Cx:y = fatty acid and CCx:y = difatty acid with $\mathrm{x}$ carbon atoms.

Figure S4 Structures of the different triterpenoid markers of birch bark tar and their putative formation pathways. The asterix for lupenone and betulone indicates that these biomolecules are native biomarkers of birch bark but their proportion is usually increased by oxidation either during tar making or after ageing. Adapted from Regert, 2004.

Figure S5 Structures of the different diterpenoid markers characteristic of pine resin and tar (asterix for abietic acid indicates that this biomolecule is absent in our samples).

Figure S6 Organic materials (samples of class C) used for decorating vessels or others external treatments. (C) Jean-Denys Strich, CNRS, CEPAM.

Table S1 List of the samples investigated and detail of analytical results by DI EI-MS and GC, GC/MS. 